\title{
O princípio de individuação (contribuição a uma filosofia africana)
}

\author{
ROGER BASTIDE \\ TRADUÇÃO RODRIGO BULAMAH \\ Universidade Estadual de Campinas, Campinas, São Paulo, Brasil \\ REVISÃO TÉCNICA LUÍSA VALENTINI \\ Universidade de São Paulo, São Paulo, São Paulo, Brasil
}

DOI 10.11606/issn.2316-9133.v27i1p220-232

O problema da individuação é um problema filosófico. Me perdoem se nesta exposição mesmo partindo de dados da etnologia africana, eu o trate filosoficamente.

Tal problema se coloca nas sociedades tradicionais? Se sim, como? É isso que veremos adiante. Mas, de qualquer forma, ele se coloca nas sociedades atingidas pelo cristianismo ou pelo Ocidente. Ele entra atualmente na reflexão dos Melanésios e dos Africanos, e estes redescobrem, a partir desse contato, mantendo-se ao mesmo tempo ligados às suas próprias tradições, as soluções que a escolástica cristã forneceu ao seguinte problema: a individuação pela matéria - a individuação pela forma.

A individuação pela matéria. É essa a reflexão que tanto surpreendeu Leenhardt, que acreditava haver ensinado a realidade da Alma aos Canaques, mas obteve como resposta de um deles que: "o que você nos ensinou é que nós temos um corpo". De fato, o Melanésio se concebia como um nó de participações; ele estava mais fora do que dentro de si mesmo, em seu totem, em sua linhagem, em sua natureza e no social; aquilo que lhe ensina o cristão é cortar essas alteridades para descobrir sua identidade - e essa identidade é marcada pelas fronteiras do seu corpo, que o isola dos outros corpos (LEENHARDT, 1947). Isso significa encontrar a solução tomista, e, para além disso, aristotélica, da individuação pela matéria enquanto a matéria é quantidade, ou seja, adição de unidades autônomas recortadas de uma mesma extensão.

\footnotetext{
1 Publicado originalmente em: BASTIDE, Roger. Le principe d'individuation (contribution à une philosophie africaine). In: DIETERLEN, Germaine (ed.). La notion de personne en Afrique noire. Paris: Colloques Internationaux du CNRS, n. 544, 1971, pp. 33-43.
} 
A individuação pela forma. O movimento carismático Jamaa que se desenvolveu nos centros industriais do sul do Katanga ao longo desses últimos anos, na maior parte das regiões do sudeste do Congo, defende que antes da sua criação, o homem já estava presente no Mawazo (plural de wazo, ideia, pensamento) de Deus e não era nem homem nem mulher, nem jovem nem velho, nem branco nem negro; ele era pura forma, diríamos nós, da inteligência divina. E é por isso que o mawazo torna-se uma sorte de conexão espiritual unindo a humanidade para além do tribalismo, em uma só família, em uma única Jamaa (FABIAN, 1966). É encontrar a solução augustiniana, e, para além disso, platônica, que funda a individuação do homem no pensamento divino enquanto Ideia (com um "I" maiúsculo).

Porém, sem dúvida, nesses dois casos, trata-se de sociedades em mutação. Compreendemos a partir disso que o problema da individuação se coloca e que ele encontra algumas das soluções próprias ao nosso pensamento ocidental. Devemos então nos distanciar desse momento de mudança para ver se o problema se coloca ta mbém nas sociedades mais tradicionais da África, nas quais, se ele se coloca, não pode naturalmente fazê-lo de mesmo modo que entre nós. Se bem que, acreditemos, nós podemos sempre traduzir os termos nativos de sua solução em linguagem moderna, a fim de melhor apreender - por analogia (já que se trata de uma questão de a nalogias semânticas) - o sentido profundo do pensamento africano, ou dos pensamentos africanos, no plural.

Começaremos pela geomancia, pois esta adivinhação - sendo ao mesmo tempo fortemente integrada a um certo número de populações do Oeste africano e de Madagascar, possuindo, por outro lado, uma origem árabe, mas fortemente transformada pelos povos pagãos - é uma transição natural entre as sociedades de hoje, em mutação, e as sociedades mais arcaicas, mas tendo contudo já assimilado elementos estrangeiros.

Nós já discutimos o problema da geomancia, mas em uma outra perspectiva, aquela do adivinho que é consultado e que não pode responder ao consultante se não definindo de saída e classificando em seguida o conjunto de eventos possíveis em um pequeno número de categorias (BASTIDE, 1968). Devemos abordá-lo agora na perspectiva inversa, aquela do sujeito que se dirige ao adivinho. O que ele o questiona é, sendo a condição suposta, o que irá lhe acontecer: se ele viaja, essa viagem sucederá bem? - se ele é casado, terá um filho, etc.? Em uma palavra, o que ele busca é - diríamos - sua definição diacrônica. Cada ser concreto está implicado em todo o sistema, - é a geomancia 
que, pela leitura dos signos, define esse sistema, - de ações e de reações recíprocas com o mundo envolvente (a doença, a morte, o nascimento) e o mundo social (a aliança ou a guerra, a inimizade ou a prosperidade); enquanto ser vivo, ele se encontra sob a dependência do que ele chama de seu Destino, que é uma sucessão de eventos, que são para ele as palavras dos Deuses sobre seu ser. Mas que em nada difere, contudo, do problema que levantamos, sob outra forma, na filosofia contemporânea, em termos de relações entre a substância e os acidentes. Em outros termos, pois entre nós ele se coloca em termos de adjetivos qualificativos (ser branco ou negro, ser filho de $\mathrm{X}$ ou filho de $\mathrm{Y}$ ) enquanto ali ele se coloca em termos de verbos, passivos (tornar-se doente, ser atingido pela morte) ou ativos (viajar, se casar). O princípio, porém, é o mesmo. Estariam os acidentes (ou os eventos) se adicionando ao sujeito para defini-lo como uma espécie de mosaico? Ou, ao contrário, é o sujeito que unifica os acidentes ao relacioná-los a ele mesmo, estruturando-os e individualizando-os? De um lado, para descobrir a origem verdadeira das diversidades individuais, é necessário ir à existência dos eventos, que os distingue uns dos outros - mas, por outro lado, sob a mobilidade cronológica desses eventos, o ser individual reside. O problema das relações entre a substância e o acidente torna-se, entre os Africanos, o problema da relação entre nossa pessoa e sua biografia (aquela que os griots recitarão mais tarde ou aquela que as tapeçarias daomeanas resumem em um certo número de desenhos recortados).

Devemos destacar aqui alguns dados:

$1^{\circ}$ ) Cada evento constitui uma categoria de alguma forma transcendente aos indivíduos e consequentemente cada uma dessas "classes" pode sempre ser comum a vários indivíduos. O papel do adivinho é justamente o de subordinar o consultante a uma dessas classes gerais. Cada classe é ligada a um dos signos da geomancia e seu sentido é dado pelo ou pelos mitos que acompanham aquele signo. A história dos homens repete a história dos deuses. Esta última constitui a lista arquetípica dos eventos possíveis que podem nos definir em nossa existência concreta. Diríamos, em termos platônicos, que cada um de nossos "acidentes" existe antes como uma Ideia de Deus.

$2^{\circ}$ ) Mas então se cada acidente, ou evento, existe de alguma forma como um Universal que pode se aplicar a uma multiplicidade de indivíduos, é a coleção de alguns desses universais ou, mais exatamente, é a ordem na qual eles se realizam, a lei de suas sequências, que é particular: é essa lei de uma biografia que constitui, para essa pessoa, o 
princípio de sua individuação.

$3^{\circ}$ ) É necessário enfim fazer uma outra observação; na geomancia, pratica-se um certo número de movimentos sucessivos e cuja significação é dada ao final por um conjunto de signos, não por um só; cada um tende a "particularizar" o evento, que é do geral para lhe fazer chegar ao particular: mas se assim o é, será que poderíamos nos contentar em dizer que o que constitui o princípio da individuação é a coleção ordenada dos eventos? Não seria necessá rio dizer, ao contrário, que este sujeito individual é a nterior à diversidade dos eventos nos quais ele será implicado? A biografia de um homem seria então o signo de sua personalidade "diferente", mas somente seu signo - de forma alguma o seu princípio.

Dizíamos que a geomancia nos fazia passar de um pensamento em mutação ao pensamento tradicional, pois ela possuía uma origem não negra. De fato, acreditamos que com ela estamos plenamente no pensamento tradicional. Pois se nós examinássemos as outras formas de adivinhação, como a da tarântula, por exemplo, nós veríamos que elas obedecem exatamente às mesmas regras: cada objeto colocado diante do buraco da aranha é signo de um evento, os eventos são classificados e não correspondem a um número infinito - para dar sua consulta, o adivinho não só enumera os objetos que foram tocados ou deslocados pela aranha e os que não o foram, ele os olha em um novo conjunto por eles formado. O sentido das partes é determinado pelo todo, ou seja, há a passagem dos eventos enquanto categorias universais do pensamento à sua particularização (o modo como eles se apresentarão) a um sujeito determinado. Mas a ambiguidade ainda subsiste entre as duas soluções possíveis: de um lado, a individuação é a consequência cronologicamente ordenada dos eventos que sucedem a tal indivíduo, e que é diferente de seu ordenamento para um outro; ou, de outro, ela reside, ao contrário, em uma unidade prévia do sujeito que particulariza esses eventos.

A adivinhação certamente nos aproxima do modo como o princípio de individuação é pensado pelos Africanos. Mas ela não traz a solução ao nosso problema, pois ela é alcançável por uma ambiguidade que só conseguiremos apreender ao seguirmos por outra rota.

Consequentemente, iremos nos engajar em outro caminho, aquele que é caro à etnologia tradicional, e que faz da sociedade africana uma "ordem" de inter-relações entre personagens e não entre indivíduos. Não que os etnólogos neguem a diversidade de 
indivíduos ao imergi-los em uma comunidade que seria primeira, que seria a única realidade verdadeira; eles reconhecem que há pessoas tímidas e pessoas audaciosas, pessoas cruéis e pessoas amáveis, mas esses caracteres se organizam em um mesmo universo, constituem a unidade última das coisas, que é a unidade de uma ordem. Uma ordem na qual a pessoa se apaga detrás da personagem, não enquanto complementariedade contingente de temperamentos múltiplos, mas que se estabelece entre "status" diferenciais. Em termos contemporâneos, diríamos que o problema que vai nos preocupar a partir de agora não é mais o das relações entre a substância e os acidentes, mas o das relações entre a forma (os status prescritos aos indivíduos pela sua posição em uma estrutura) e a matéria (a diversidade dos caracteres ou das existências particulares).

É evidente que o Africano se define primeiramente por sua posição, ele é o filho caçula ou o primogênito, ele é marido, ele é pai, ele é chefe. Quando o questiona mos sobre o que ele é, ele se situa em uma linhagem, ele marca seu estatuto em uma árvore genealógica. Mas é necessário notar que esses status definem o indivíduo em suas relações com alguma coisa que lhe é exterior, a ordem social na qual ele se insere. Sendo cada estatuto ligado, de fato, a um papel, a posição determina certas atitudes, certos comportamentos, modela então a conduta e, para além da conduta, a afetividade e a mentalidade. Fato é que ao curso de sua vida, uma mesma pessoa muda de status; de saída, ela é uma criança, em seguida, passa ao estatuto de adulto, de esposa, de pai, de velho. Em resumo, muda-se a personagem. O que não muda é a ordem ela mesma, pois ela constitui uma certa estrutura global da sociedade. O que faz com que se nós quisermos encontrar o princípio de individuação a partir dos papéis encenados ou das personagens, a única unidade que nós esperaríamos seria aquela da sociedade global. Compreender o africano como personagem, é compreendê-lo enquanto uma máscara. Mas atrás das máscaras, é necessário que ele possua um rosto. $\mathrm{O}$ fato de que os indivíduos se organizem em um mesmo universo prova que ao lado da individualidade da pessoa, existe, em outro nível, a unidade última das coisas. Ele não pode, por outro lado, destruir esse outro fato de que os indivíduos, alterando de estatutos ao longo de suas promoções, constituam também 'unidades'.

No fundo, o que acorre com os africanos não é tão distante daquilo que acontece entre nós. Os psicólogos que se colocaram o problema da unidade e da identidade do indivíduo a nexam essa unidade e essa identidade a elementos sociais, a permanência de 
um nome, a existência de um curriculum vitae, a possessão de um documento nacional de identidade. Dizendo de outro modo, somos como a faca, cujo cabo já trocamos e depois, mais tarde, trocamos também a lâmina, e sobre a qual dizemos ser a mesma faca, enqua nto, de fato, nenhum dos elementos antigos permanecem... Mas diríamos, quanto a nós, que esses elementos sociais, como os eventos da adivinhação, não são nada além de signos; eles não possuem realidade, indicativa de unidade ou de identidade, pois remetem, por outro lado, à individuação de um sujeito. O segundo caminho percorrido não nos parece então poder nos conduzir muito mais longe do que o primeiro; ele nos mostra que a matéria, para se realizar na vida concreta, deve passar pela forma ou uma sucessão de formas unificantes; mas unificantes de que? Não se trata como em São Tomás de Aquino, que a forma do estatuto torna-se por si mesma particular e determinada. E se é verdade que é impossível de compreender o indivíduo fora de sua relação com os outros, não é que ele seja esse conjunto de relações, mas é que enqua nto sujeito individual, ele está implicado em uma ordem de dependências recíprocas que o excede ${ }^{2}$. Trata-se de algo completamente diferente. Essa dialética da forma (estatutária) e da matéria (quantificada em indivíduos) nos surge exatamente quando refletimos sobre os dois fenômenos que constituem os dois polos de um continuum.

Os ancestrais se dividem em dois grupos, aqueles Ancestrais próximos, que chamamos às vezes de "mortos vivos" e os ancestrais distantes, que somente enquanto o nome e o lugar em uma genealogia. Ora, esses ancestrais distantes não são nada além disso: uma posição em uma linhagem, eles são desprovidos de personalidade (cf. MBITI, 1969). O sujeito desaparece, ele possui somente uma forma pura. Por outro lado, na doutrina da reencarnação, aquilo que revive do avô em seu neto, não é necessariamente um sujeito ancião; se é tomado o nome de seu avô, isso não significa que haverá semelhanças com ele (se bem que, buscam-se sempre de forma retrospectiva semelhanças físicas, tiques ou analogias de caráter); mas, por outro lado, constantemente o que se encarna é o estatuto do avô. Herda-se, por exemplo, alguns de seus poderes religiosos e ocorre de o Pai ter uma atitude de respeito para com seu filho, pois este filho reencarna o Pai do Pai. No outro polo do continuum, teríamos então uma forma constituinte, constituinte ao menos de uma parte do sujeito. Em resumo, o segundo caminho, sem nos levar ainda ao princípio da individuação, dele nos aproxima. Demos, creio eu, um passo à

\footnotetext{
2 Comentário de A. FOREST sobre São Tomás de Aquino.
} 
frente.

Não é sem propósito que essa discussão se situe em um volume que trata da noção de Pessoa em África e que uma ampla pesquisa foi levada a cabo sobre os componentes da Pessoa nas mais diversas etnias africanas. $\mathrm{O}$ que parece surgir deste inventário etnológico é a pluralidade dos elementos constituintes da pessoa; o princípio de individuação se coloca, então, em última análise, para a maior parte das etnias africanas do seguinte modo: o que constitui a unidade dessa pluralidade?

Mas deve-se ir ainda mais longe. Alguns desses elementos fazem o indivíduo sair de si mesmo para participar de outras realidades. Na medida em que ele reencarna um Ancestral, por exemplo, existe nele uma porção da linhagem. Na medida em quem ele é ligado a um totem, ele possui, ao lado de sua alma interior, uma "alma exterior", seguindo a expressão de Frazer. Na medida em que ele é possuído por um espírito [Génie], ele é, ao mesmo tempo, ele e Outro. Na medida em que ele é um Gêmeo, cujo irmão é um gêmeo do mato [jumeau de la brousse], ele rompe a distância que o separa do espaço sagrado, do mundo misterioso que palpita próximo a ele. Em resumo, o indivíduo é mais que uma pluralidade de almas corporais (alma do dedão do pé, alma do estômago, alma do coração...) e de almas psíquicas (a Sombra, o Duplo, o Sopro...), ele só existe na medida em que está "fora" e é "diferente" de si. Como é possível a partir disso, se não por etnocentrismo e generalizando aos Africanos nossas próprias concepções, falar de indivíduo? Fora do nome que lhe foi dado, ele só existe concretamente para e na rede que o religa ao tempo dos Ancestrais, ao espaço do Mistério vivo, aos Totens e aos Deuses. Fora dessa rede, ele não existe mais. O que pode constituir a unidade dessas participações à outra coisa, fora da qual não há mais nada além do imenso vazio?

A concepção ocidental define o indivíduo ao mesmo tempo pela sua unidade intrínseca; ele é indivisum in se; e, por outro lado, pela sua autonomia; ele se coloca pela sua oposição; ele é ab alio distinctum. Ora, essas duas características faltam à pessoa tal como a concebem os Africanos, que é divisível e não se distingue. Eu disse acima que gostaria de levá-los ao terreno da filosofia. Pouco importa que, seguindo as etnias, tenhamos um corpo e várias almas, a té mesmo muitos princípios de vida corporal, três, quatro, cinco ou sete, até mais; pouco importa que a ideia do gêmeo do mato não exista em todos os lugares, que ele seja, aqui, ligado à placenta e, em outro lugar, não, que o mapa da África possua suas regiões de reencarnação, aquelas do totemismo, e outras regiões sem 
reencarnação e sem totemismo. O que importa, é a existência em todas as sociedades tradicionais, ao menos pelo que conheço, do que chamaríamos de os dois anti-princípios de individuação: a pluralidade de elementos constitutivos da personalidade e a fusão do indivíduo em seu a mbiente ou seu passado; em resumo, em sua alteridade.

E, contudo, é evidente que os Africanos, como nós, reconhecem os indivíduos enqua nto indivíduos. Talvez até mesmo mais do que nós. Desde Lévy-Brühl, e a partir da linguística, isso foi devidamente sublinhado. Seu conhecimento do mundo é um conhecimento mais concreto do que abstrato, mais de imagens que de conceitos. Lá onde vemos um rebanho, os Nuer vêm vacas. Lá onde vemos a floresta, os Bantu vêm Árvores. Estamos então face a uma aporia, que podemos resolver somente de modo progressivo, a unidade do indivíduo supondo como necessidade prévia a unidade da pessoa humana. Seria esta a unidade de um agregado, de um nó de participações, ou de uma estrutura? Esta será nossa primeira questão.

De saída, é preciso levar em conta que os diversos constituintes da pessoa não aparecem logo de cara, no momento do nascimento; na maioria das vezes, eles se apresentam um após o outro. Identificação do nascido à linhagem pelo Nome. Ao ancestral que ele reencarna pela adivinhação. À fonte de vida totêmica. Incorporação da forma do "Personagem" nas virtualidades da "pessoa" infantil, no momento da iniciação tribal. Finalização da alma feminina, incompleta entre as jovens moças, pelo casamento que a permite realizar-se pela participação na alma masculina. Finalização da alma masculina pela sua práxis no seio da sociedade. Ora, essa ideia da Pessoa como criação contínua está em perfeito acordo com os mitos da criação do Universo, que comportam sempre "períodos" e se situam em uma perspectiva diacrônica, a Fala não sendo instantaneidade, mas só podendo existir ao se desenvolver em um Discurso. De qualquer forma, que essa criação progressiva da pessoa seja somente analógica ou que ela seja uma repetição da criação do cosmos, um fato permanece, uma certa unidade da Pessoa se desprende, ou mais claramente: ela é postulada pelo Ciclo da Vida do indivíduo.

Mas essa unidade postulada é ela uma unidade pensada? Para o Africano, não se pode dizer que o princípio de unidade seja o corpo, pois há muitas almas corporais, e mesmo que exista uma unidade corporal, o corpo não pode comunicar sua unidade à alma. Porque há muitas almas espirituais: força vital, sombra, duplo... e nós devemos reconhecer a independência desses diversos princípios. Sabe-se que o pensamento africano é um 
pensamento por correspondências místicas e não, como a nossa, por "encaixotamentos" lógicos. Não podemos, então, encontra r neles, como entre os escolásticos que partiam da existência de três almas - uma alma vegetativa, uma alma sensível e uma alma intelectual -, a solução do encaixotamento: elas estão uma na outra como o triângulo está no tetrágono e o tetrágono está no pentágono. Não podemos descobrir nada além de uma solução nas correspondências. Ou seja, é necessário buscar a chave da realidade individual no conjunto de relações, que ligam o homem aos diversos princípios constitutivos do Cosmos e ao conjunto de relações sociais (aqui compreendidas, que esteja claro, que ele mantém com os Mortos). A antiga etnologia, mais preocupada em nos diferenciar dos primitivos e de buscar o que nos distingue, não está interessada em descobrir esta "chave"; ela se ateve à ideia de pluralidade das almas. Ela não quer ver nada além de uma unidade de agregação. A etnologia contemporânea, a partir dos trabalhos de Griaule, encontra a chave de uma unidade estrutural na ordem do simbólico. Decerto, esta unidade estrutural variará segundo os povos, ou seja, segundo as diversas lógicas de correspondência entre os elementos do cosmos (ou do social) e os elementos da pessoa (ou do indivíduo). Mas me parece que essas variações poderiam se exprimir, geométrica ou mecanicamente, como um só sistema, que seria um sistema de "composição de forças" - ou melhor, filosoficamente, como um só sistema, que seria aquele do jogo das dialéticas, de complementariedade, de conflitos, de suporte, de exclusão, entre princípios descontínuos. A impureza nos priva momentaneamente de tal princípio a que nos caberá reintroduzir para que a pessoa se mantenha intacta. $\mathrm{O}$ sono permite que escape um de nossos princípios, no espaço de uma noite, para voltar a nós no despontar da manhã. A morte nos atinge progressivamente, simplificando o teorema da composição das forças pelo desaparecimento ou ao menos o enfraquecimento de algumas dessas forças.

Desse modo, o pluralismo das Almas não impede a unidade da Pessoa. Mas essa é uma unidade formal. A de um equilíbrio. Concretamente, há estados sucessivos de equilíbrio, de desequilíbrio e de reequilíbrios entre forças que mergulham para além de nós mesmos, estando em nós mesmos, sendo nós mesmos. Senhora Calame-Griaule escreve que, para os Dogon, a personalidade está submetida à oito "polos de identificação" que parecem se neutralizar dois a dois, e que se deslocam de lugares exteriores à pessoa, onde se mantém em reserva, aos órgãos no corpo, onde permanecem temporariamente. A vida psíquica pessoal se define, então, por itinerários (CALAME-GRIAULE, 1965). P. 
Tempels escreve, à propósito dos Bantu, que o corpo, o sopro, a sombra... não são nada além de manifestações sensíveis da pessoa viva, muntu, e ele faz dessas forças vitais particulares, determinadas, "momentos ou nós de alta tensão vital" (TEMPELS, 1949). Essas duas citações são suficientes. Elas mostram, com efeito, que as diversas populações africanas podem possuir sistemas distintos - a menos que diferentes sejam somente as expressões desses sistemas em linguagem ocidental, algo que sería mos facilmente levados a pensar -, mas a definição de unidade da pessoa está sempre dada em termos de unidade formal ou estrutural, seja em “itinerários” ou caminhos, seja em “tensões” e em "nós”.

Mas essa unidade não é nada além da base do princípio de individuação e não este princípio por si só, pois se trata de uma estrutura ou da forma que reveste o jogo dialético de princípios ou de elementos diferentes, aquilo que os etnólogos chamam pelo nome de almas simples. Uma comparação com a psica nálise de Lacan escla recerá o que queremos dizer. Lacan distingue a ordem do simbólico, que fornece a lei de composição formal de toda estrutura subjetiva, o Pai ou Grande Outro - o Eu - o id ou objeto indeterminado e a ordem imaginária, que forma uma combinatória de significantes diferenciados, distinguindo um indivíduo de um outro. Se compreendemos bem, há em toda pessoa, por exemplo, o polo de identificação com o Pai, que pode constituir a identidade a partir da alteridade (a cadeia de gerações na linhagem), mas esse Pai ao qual se identifica pode se manifestar pelos mais diversos fantasmas, seguindo as variadas circunstâncias a través das quais pode-se viver o complexo de Édipo ou sua liquidação, até mesmo, como no caso dos para nóicos, existir no indivíduo como “vazio” que pode vir a realizar-se numa Mãe fálica. Pois bem, buscando a estrutura formal da Pessoa humana, nos mantivemos na ordem do simbólico; devemos passar agora - para definir o que nos diferencia uns dos outros àquilo que Lacan chama de ordem do imaginário.

Porém, é claro, esta ordem do imaginário só pode se desenrolar na ordem do simbólico: ela é a explicação na concretude de um Ser. Por exemplo, no que se refere ao princípio espiritual da "reencarnação de um Ancestral", no qual o indivíduo reencarnará este ou aquele Ancestral, por exemplo, seu bisavô paterno ou o chefe da linhagem, ele manifestará em sua vida esta ou aquela característica - no que concerne a alma exterior ou o totem ao qual nós participamos, algumas das características do animal totêmico deverão fortemente repercutir ao nível do temperamento individual, temperamento real, no que concerne os Fon, para os membros da linhagem que tem origem na pantera Agasu, 
temperamentos rotineiros para os indivíduos dos clãs que se ligam ao cavalo, ao porco ou a outros animais domésticos. Não gostaríamos de entrar aqui na discussão entre Seligman, que fala da "identificação" do Negro com o boi cujo nome ele porta, e EvansPritchard que pensa que o processo é de comunicação através de um animal com o Rebanho e, para além deste, com a divindade. Parece ser o mesmo caso já que a escolha de um boi determinado deve ter algum efeito na elaboração de uma personalidade particular e, em segundo lugar, que a passagem do boi dado pelo pai ao boi dado pela iniciação traduz-se na gênese do indivíduo - para particularizar o desenvolvimento na duração - nas confrarias de possessão, o suplemento de alma que provém do fato de um Deus habitar em sua Esposa mística não se traduz somente no curso do transe, onde se encena a história arquetípica do Deus, mas, como eu ponderei no caso das religiões AfroBrasileiras, por uma remodelagem da personalidade que vai, em seus comportamentos mais cotidianos, agir segundo a característica da Divindade (BASTIDE, 1959). Aqui, embora não adentremos nas discussões possíveis para saber se trata-se de uma "imitação de Nosso Senhor Jesus Cristo” ou se a iniciação possui como objetivo fazer ressurgir do inconsciente a personalidade verdadeira do indivíduo, que a sociedade havia rejeitado ou reprimido, e que pode a partir daí, ao se divinizar, se desdobrar na aceitação da comunidade; pouco importa; o que é essencial nessa exposição é - em termos psicanalíticos - que o Mito torna-se Fantasia ${ }^{3}$, ou seja, princípio de ações particularizadas. Com a possessão, passamos, em certa medida, do individual ao genérico. É o que traduzimos ao dizer que encontramos entre os Yoruba, as filhas do Fogo, as filhas da Água, as filhas da Terra e, com isso, certa identificação às qualidades do fogo, da água, da terra. A entrada em uma Confraria traduz a passagem do adjetivo qualifica tivo em substantivo ontologizado. Mas este não é o único caso de relação possível entre o individual e o genérico. O estudo da organização social dos africanos nos mostra que em muitas dessas formas de organização, o caráter dos indivíduos é determinado, de alguma forma, topologicamente, pelo seu nascimento nesta ou naquela metade, neste ou naquele bairro; seguindo, com efeito, que sendo do bairro de cima ou de baixo, exibiremos um caráter mais viril ou mais feminino - mais guerreiro ou mais sensível (cf. RADCLIFFE-BROW; FORDE, 1950; LÉVI-STRAUSS, 1962) ${ }^{4}$. Rencontramos assim, em um outro nível, o

\footnotetext{
3 N.T.: "Fantasia" traduz aqui o conceito psicanalítico de "Fantasme" (ou "Phantasie"), seguindo o costume nas traduções dos textos de Jacques Lacan para o português.

${ }^{4}$ Há muitos exemplos disso em Radcliffe-Brown e Forde (1950). Lévi-Strauss (1962) reconheceu essa modelagem da pessoa e de suas condutas entre os Ameríndios.
} 
pluralismo. Naturalmente, a solução da antinomia plural-singular é do mesmo tipo que aquele que nos pareceu válida para a noção de pessoa. A unidade do indivíduo pode se traduzir por uma fórmula que enumerará as diversas espécies que o subsumem; é por isso que, por outro lado, ele recebe muitos nomes, cada um deles arranjando-o no interior de uma dessas categorias. Desse modo, os nomes não criam a personalidade, eles são somente as marcas que o identificam a uma classe e se eles são múltiplos é que adentramos em uma série de classes diferentes. Assim, quando passamos da noção de pessoa àquela do indivíduo singularizado, despreende-se, ao lado de uma lógica da relação, uma lógica da atribuição. Nos dois casos, e é isso que faz com que as soluções sejam análogas, temos unidades estruturais; mas, no que corresponde à Pessoa, trata-se de uma estrutura de relações entre princípios vitais exteriores e interiores e, quanto às suas vidas no interior, trata-se de suas relações dialéticas. No que corresponde ao indivíduo, não se trata de uma estrutura de classificações (com esta diferença com relação a nós, pois que talvez não se trate mais de classes que se encaixotam, no qual o indivíduo não poderia explicar sua singularidade - mas de classes independentes, pertencendo a sistemas diversos de classificações ecológicas, sociais, cosmológicas, metafísicas, o que faz com que a singularidade resulte da fórmula, que muda de uma pessoa à outra, de seus pertencimentos).

Espantaria talvez, que após ter proclamado a especificidade do princípio de individuação em África, nós o traduzimos em termos ocidentais. Trata-se do fato de que há somente uma Razão que pensa, em todas as partes, por conceitos e imagens ou por símbolos e signos. Assim, para melhor se fazer compreender, é sempre permitido transcrever um mesmo processo lógico ou filosófico em sistemas conceituais, equivalentes qua nto aos seus significados profundos.

\section{Referências Bibliográficas}

BASTIDE, Roger. La connaissance de l'évènement. In: Perspectives de la Sociologie contemporaine. Paris: Presses Universitaires de France, 1968, pp. 159-168.

Le Candomblé de Bahia. Paris: Mouton, 1959.

CALAME-GRIAULE, G. Ethnologie et Langage. La parole chez les Dogon. Paris: Gallimard, 1965.

FABIAN, Johannes. Dream and Charisma: 'Theories of dreams' in the Jamaa-movement (Congo). In: Anthropos, vol.61, n.3/6, 1966. 
MBITI, John S. African Religions and Philosophy. Londres, Ibadan, Nairobi: Heinemann, 1969.

LEENHARDT, Maurice. Do Kamo. La personne et le mythe dans le monde mélanésien, Paris: Gallimard, 1947.

TEMPELS, R. P. Placide. La Philosophie Bantoue. Paris: Présence Africaine, 1949

RADCLIFFE-BROWN, Alfred; FORDE, Daryll. African Systems of Kinship and Marriage. Londres: Oxford Univ. Press, 1950.

LÉVI-STRAUSS, Claude. Le Pensée Sauvage. Paris: Plon, 1962.

autor Roger Bastide

Sociólogo francês, ocupou a cátedra de Sociologia I da Universidade de São Paulo, realizando pesquisas sobre religiões afro-brasileira, com especial atenção ao candomblé.

tradutor Rodrigo Bulamah

Possui graduação em Ciências Sociais e Mestrado em Antropologia Social, ambos pela Universidade de Campiinas, e doutorado em Anthripologie Sociale et Ethnologie pela Ecole de Hautes Études em Sciences Sociales, em co-tutela com a Universidade de Campinas.

Recebido em: 14/04/2017 Aceito para publicação em: 21/07/2017 